\title{
Let's Read: designing a smart display application to support CODAs when learning spoken language
}

\author{
Katie Rodeghiero, Yingying 'Yuki' Chen, Annika M. Hettmann, Franceli L. \\ Cibrian
}

Published: 30 November 2021

\begin{abstract}
Hearing children of Deaf adults (CODAs) face many challenges including having difficulty learning spoken languages, experiencing social judgment, and encountering greater responsibilities at home. In this paper, we present a proposal for a smart display application called Let's Read that aims to support CODAs when learning spoken language. We conducted a qualitative analysis using online community content in English to develop the first version of the prototype. Then, we conducted a heuristic evaluation to improve the proposed prototype. As future work, we plan to use this prototype to conduct participatory design sessions with Deaf adults and CODAs to evaluate the potential of Let's Read in supporting spoken language in mixedability family dynamics.
\end{abstract}

\section{Keywords:}

CODAs; Deaf; Smart display; Reading; Mix-ability.

\section{Introduction}

Studies have shown that $90 \%$ of Deaf individuals with children have hearing children [10]. These families with mixed-abilities have a unique dynamic as it is common for children to learn to communicate in both Sign and spoken languages simultaneously as well as having to learn verbal languages through nontraditional measures [5]. These venues include learning spoken language by listening to people around them or the TV instead of learning from their parents [5]. Hearing children of Deaf adults (CODAs) can have difficulties learning spoken languages given that their first language may be Sign language [5].

One way to support spoken language learning is by reading. Research has shown that reading can provide opportunities for CODAs to interact with both Sign and spoken language at home [15]. Deaf adults usually use printed books as a tool to combine visual signed language with the written language. If they have access to computers/technology, they use it as a tool to support CODAs in becoming independent readers by using these online resources [15]. The printed books allow for a range of activities,

\footnotetext{
Rodeghiero, Katie., Chen, Yingying 'Yuki'., Hettmann, Annika M., Cibrian, Franceli L.

Chapman University

Orange, California

rodeghiero@chapman.edu,yingchen@chapman.edu,

hettmann@chapman.edu, cibrian@chapman.edu
}

including daily bedtime stories, as a means to engage the children in reading activities.

Therefore, in this project, we explored the design space of Let's Read, a smart display application to assist Deaf adults during the teaching/learning process of the spoken language of their children (Figure 1) by scanning a children's books page, highlighting the individual words, and reading them aloud. Nonverbal or Deaf adults can then sign along with the reading so that hearing children can associate Sign language with specific words and sentences.

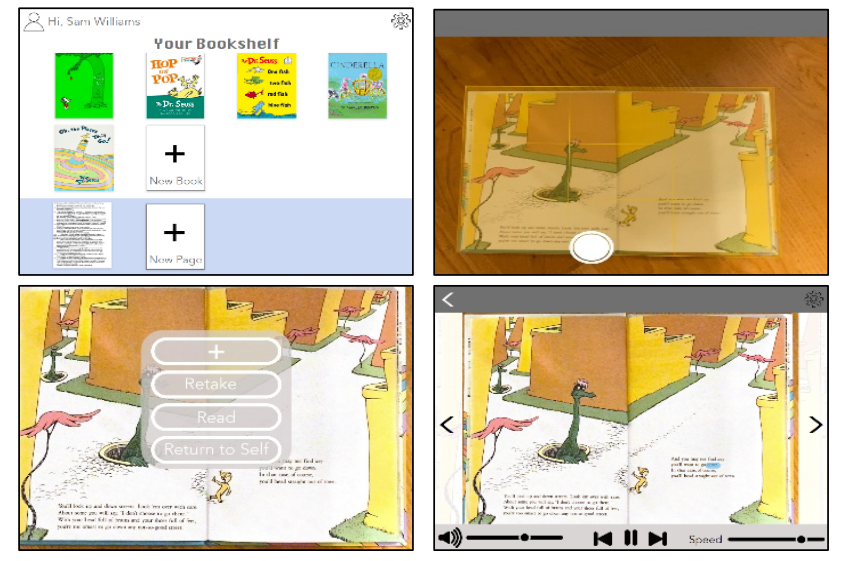

Figure 1. Screenshots of Let's Read. Images clockwise from top left: bookshelf to select books; scanner function; scan accept function; visualization of reading functionality of scanned pages.

\section{Related Work}

There is a lot of research around assistive technology supporting Deaf communities using mobile devices $[1,8,11-13,18]$. Assistive technology has been used to support communication between medical responders and Deaf individuals [2] or to provide pharmaceutical instructions in an accessible manner [14]. For example, SignSupport is a mobile communication tool to support a Deaf individual in understanding usage direction for medication dispensed at a pharmacy by translating medicine instructions given in English text to Sign language videos relayed using a mobile phone. A usability study with eight Deaf participants and eight pharmacists found that the system is easy to use, but some videos could be misinterpreted by Deaf users [14]. 
Using videos of Sign language has also been used to provide real-time communication between Deaf and hearing individuals [9], even in virtual environments [23]. Another approach was to use speech-to-text functionalities on a tabletop [19]. Overall, this body of work shows that assistive technology can be used to support the communication for Deaf communities and the interaction between people with mixed-abilities. Therefore, our work is focused on how we can support CODAs when interacting with their caregivers, especially when learning spoken languages while reading.

\section{Methods}

To understand the process of how Deaf adults teach their children to read and speak in both Sign and verbal language, we followed a simple interactive design process. First, to discover the requirements and given the restrictions to conduct in-person data collection, we collected data from blog-style websites (e.g., [22, 3, 20]), videos (e.g., [21, 7, 6]), and reports (e.g., [16]). All the data collection was in English, and most of them targeted the Global North population. People with hearing problems, especially Deaf adults with hearing children, often use these sites when looking for resources to support their hearing children. Individuals without auditory impairments can also use these sites to support Deaf individuals or learn more about the Deaf community.

We conducted a content analysis using techniques from thematic analysis and open coding [4]. The resulted themes were grouped using an affinity diagram. Next, we conducted brainstorming and visioning sessions to proposed design alternatives and potential visions of prototypes. During the sessions, we discussed the advantages and disadvantages of each vision $(n=3)$. Finally, we selected the prototype that led to Let's Read, a smart display application. We developed a storyboard and the first version of Let's Read prototype. We conducted a heuristic evaluation with seven experts in HCI, assistive technology, and app development to get their feedback. This allowed us to improve our first version and design the final prototype.

\subsection{Limitations}

The data collection was conducted using a thematic analysis from posts and data available in online communities. Therefore, to date, we do not have direct feedback from a Deaf parent. Despite that, we believe that their concerns, challenges, and opportunities are reflected in comments and videos from online resources. We developed a low fidelity prototype and, as a first stage, conducted a heuristic evaluation with experts to improve our proposed prototype. With this feedback, we created a more robust prototype that can be used to conduct co-design sessions with Deaf parents and CODAs to then evaluate the acceptability and efficacy.

\section{Results}

In the thematic analysis, we grouped our themes in parents (and/or adults) and children's perspectives (see more details in Table 1). Overall, we found that reading a story together can be a good strategy to support CODAs when learning spoken language.

Therefore, we envisioned and sketched the big picture of three potential assistive technologies that CODAs and their guardians could use. One resembled a pen with a scanner and voice assistance capabilities, and the other two resembled our current Let's Read prototype, with the difference being that one would be used on a computer and the other on a smart display. After discussing each proposed idea's advantages and disadvantages, we selected to design a smart display tablet application augmented with voice assistant capabilities and a display as we concluded a tablet would be the easiest technology to interface with while spending time with a child. It is called Let's Read (Figure 1).

Let's Read is be able to scan current favorite physical books from the child's bookshelf. Those books are available on the bookshelf page of the app, as many children like to read the same story multiple times. The application is able to scan the pages and transform the words into a spoken language that sounds "natural" so the child is able to mimic those spoken words.

When the adults and CODAs select the book to read, the application highlights the current word so the guardians can synchronize their signing to the highlighted and spoken word. It should be noted that the display is adaptable; this is, the application makes the highlighted words more visible by either enlarging, zooming in, or tracking them along with the page so the guardians can easily see the word and translate it into Sign language. In this manner, the CODAs have access to both Sign and spoken language.

Table 1. A summary of the findings for our thematic analysis

\begin{tabular}{|c|c|c|}
\hline & Problems & Srategies \\
\hline $\begin{array}{l}\text { Deaf } \\
\text { adults }\end{array}$ & $\begin{array}{l}\text { - It is hard for adults to understand what their child wants to } \\
\text { communicate [22]. } \\
\text { - Parents are required to send their children to speech therapy } \\
\text { [21]. } \\
\text { - Parents might ask CODAs to interpret conversations that } \\
\text { can lead to family tensions [22]. } \\
\text { - Sometimes CODAs take advantage of their parents' } \\
\text { inability to hear [3]. }\end{array}$ & $\begin{array}{l}\text { - Expose hearing children to spoken languages for five to ten } \\
\text { hours per week so the child learns the language [20]. } \\
\text { - Parents can hire professional interpreters to interpret } \\
\text { conversations that are not appropriate for children [22]. } \\
\text { - Parents encourage their children to express their feelings and } \\
\text { show them how to deal with discrimination [22]. } \\
\text { - Buy hearing aids for themselves to improve their hearing } \\
\text { ability [16]. }\end{array}$ \\
\hline CODAs & $\begin{array}{l}\text { - Having Sign language as their first language [21]. } \\
\text { - Greater responsibilities at home [22]. } \\
\text { - Interpret conversations for their parents when they go out } \\
\text { with their family [16]. } \\
\text { - Teachers might think that they have lesser intellectual } \\
\text { capacity because of their bilingual nature [16]. } \\
\text { - People assume that they are Deaf when they sign with their } \\
\text { parents in public [22][16]. }\end{array}$ & $\begin{array}{l}\text { - Learn spoken language and Sign language at the same time } \\
\text { using technology [20]. } \\
\text { - Learn to communicate with their parents and express their } \\
\text { feelings [22]. } \\
\text { - Understand the difficulties their parents are facing rather } \\
\text { than taking advantage of their parents [22]. }\end{array}$ \\
\hline
\end{tabular}




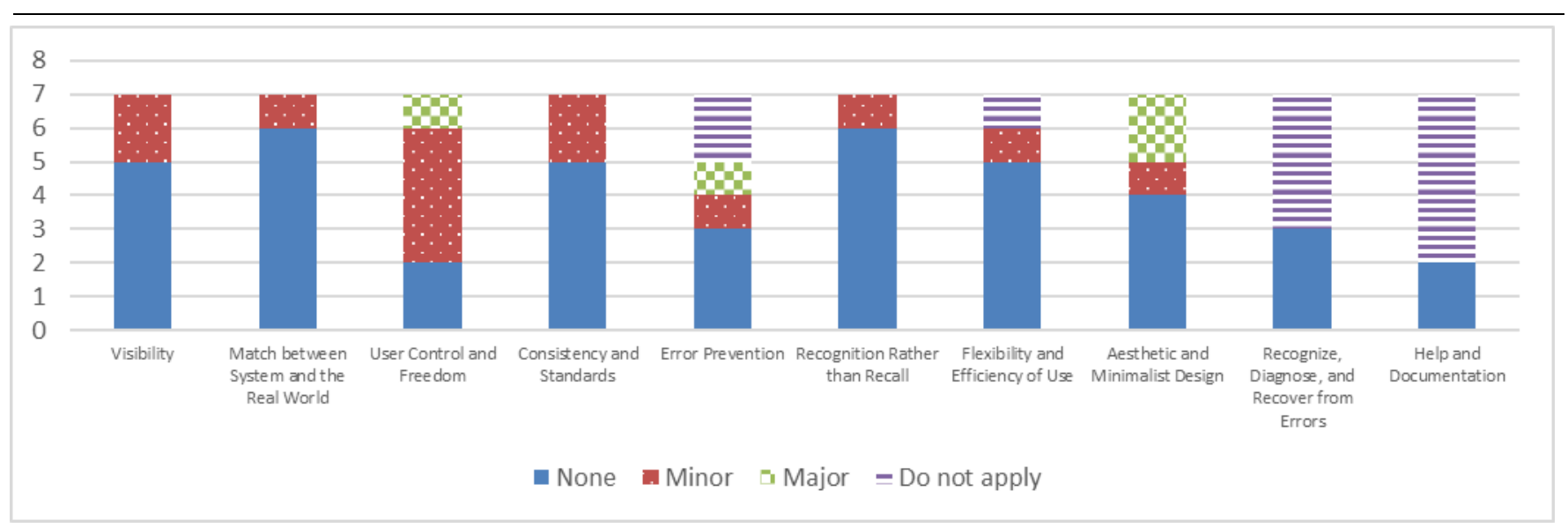

Figure 2. A bar graph showing the scores for each Heuristic.

Another important feature is the ability to customize playback speed and repetition of words. This feature allows the parent or user to repeat the word or phrase and sign the same section multiple times when needed.

\subsection{Heuristic Evaluation}

Seven experts in HCI with at least two years of experience designing applications supporting children or people with disabilities rated the first version of the prototype using the Usability Heuristics for User Interface Design [17]. They watched a video from the prototype and then scored each of the heuristics as "none," "minor," "major" problem, or "Do not apply." After that, they added observations for each heuristic, and, in the end, they were able to add general comments.

Overall, we found that the visibility, match between system and the real world, consistency and standards, recognition rather than recall, and flexibility and efficiency of use have none or minor problems. However, user control, error prevention, and minimalistic design must be improved (Figure 2). According to the evaluators' comments, they mentioned that some icons, instructions, and flow of the app should be improved. Therefore, we re-designed those characteristics in the final version of the prototype, as shown in Figure 3.

Before

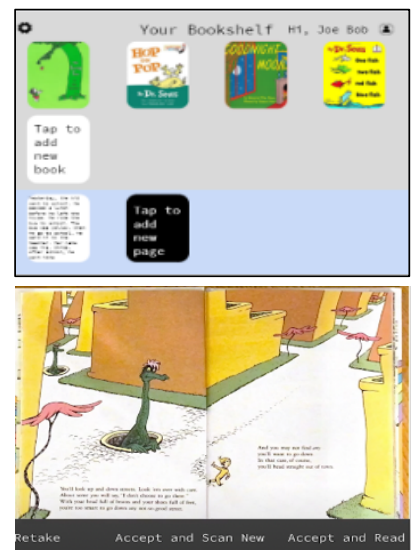

After

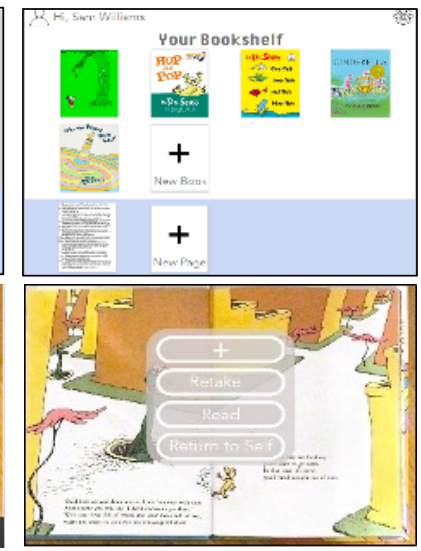

Figure 3. Screenshots showing the changes from Let's Read interfaces. Top, previous v. current versions of the bookshelf. Bottom, previous v. current versions of scan accept function.
In the re-designed version of the app, we integrated a more minimalist design that focused on utilizing icons instead of words and making the user experience more seamless and intuitive. Two examples of this are utilizing a "+" to prompt the user to add a new book or page and decreasing the amount of text while positioning the buttons in a more central area on the screen.

\section{Conclusion}

Hearing children and their Deaf parents often experience difficulties communicating with one another as a result of language barriers. To expose CODAs to more spoken languages and support bonding between parent and child, we proposed designing Let's Read, a smart display application using text-tospeech technology to read stories aloud while highlighting the words so Deaf guardians can also tell the story using Sign language.

We envision that Let's Read will make storytelling more accessible for both Deaf adults and hearing children and can be utilized in more everyday technology so that effortless communication can become more common.

As future work, we will conduct participatory design sessions with Deaf parents and CODAs to refine our current prototype by considering their perspective and deploy the application to then conduct a user study involving the targeted users. Moreover, we would like to expand our current project with Global North and South participants to support multiple languages, diverse stories, and cultures.

\section{Acknowledgments}

We would like to thank Nikki Poentis, who contributed to the data collection and the reviewers from the heuristic evaluation.

\section{References}

[1] Bragg, D. et al., (2016). A personalizable mobile sound detector app design for deaf and hard-of-hearing users. ASSETS 2016 - Proceedings of the 18th International ACM SIGACCESS Conference on Computers and Accessibility: 313.

[2] Buttussi, F. et al., (2010). Using mobile devices to support communication between emergency medical responders and deaf people. ACM International Conference Proceeding Series: 7-16.

[3] California School for the Deaf - Fremont. Our January 2020 Storysigners: Michele Berke and Tom Holcomb. Retrieved from 
https://www.facebook.com/watch/?v=2469574539968257

[4] Charmaz, K. (2006). Constructing grounded theory: a practical guide to through qualitative analysis. Sage Publications Ltd, London.

[5] Clark, K. (2003). Children of Deaf Adults: CODA's: Communication \& parenting issues in families with Deaf parents and hearing children. ASL University. Retrieved from https://www.lifeprint.com/asl101/pageslayout/coda.htm

[6] Deaf Counseling Center, (2019). CODAs: Kalista and Calvin's Story. YouTube. Retrieved from https://www.youtube.com/watch? $\mathrm{v}=\mathrm{o}-$ sxWCvI210\&ab channel=DEAFCOUNSELINGCENTER

[7] Deaf Missions. 2019. Children of Deaf Adults. Youtube. Retrieved from https://www.youtube.com/watch?v=iULz4Qn79xA\&ab_chan nel=DeafMissions

[8] Gorman, B. M. \& Flatla, D. R. (2014). VisAural: A Tool for Converting Audible Signals into Visual Cues.

[9] Gugenheimer, J et al., (2017). The impact of assistive technology on communication quality between deaf and hearing individuals. Proceedings of the ACM Conference on Computer Supported Cooperative Work, CSCW: 669-682.

[10] Hadjikakou, K. et al., (2009). The experiences of cypriot hearing adults with deaf parents in family, school, and society. Journal of Deaf Studies and Deaf Education 14, 4: 486-502.

[11] Jain, D. et al., (2015). Head-mounted display visualizations to support sound awareness for the deaf and hard of hearing. Conference on Human Factors in Computing Systems Proceedings 2015-April: 241-250.

[12] Jain, D. et al., (2020). HomeSound: An Iterative Field Deployment of an In-Home Sound Awareness System for Deaf or Hard of Hearing Users. Conference on Human Factors in Computing Systems - Proceedings.

[13] Yoshihiro, K. et al., (2013). Light-emitting device for supporting auditory awareness of hearing-impaired people during group conversations. Proceedings - 2013 IEEE International Conference on Systems, Man, and Cybernetics, SMC 2013: 3567-3572.

[14] Motlhabi, M. B. et al,. (2013). SignSupport: A Limited Communication Domain Mobile Aid for a Deaf patient at the
Pharmacy. Southern African Telecommunication Networks \& Applications Conference: 173-178. Retrieved from http://hdl.handle.net/10566/1120

[15] Mounty, J. et al., (2014). How deaf American Sign language/English bilingual children become proficient readers: An emic perspective. Journal of Deaf Studies and Deaf Education 19, 3: 333-346.

[16] National Institute on Deafness and Other Communication Disorders. (2021). Quick Statistics About Hearing. NIH. Retrieved from https://www.nided.nih.gov/health/statistics/quick-statisticshearing

[17] Nielsen, J. (1994). Enhancing the explanatory power of usability heuristics. Conference on Human Factors in Computing Systems - Proceedings: 152-158.

[18] Phillips, A. J. et al., (1994). Experience of using vibrotactile aids with the profoundly deafened. European journal of disorders of communication 29, 1: 17-26.

[19] Piper, A. M \& Hollan, J. D., (2008). Supporting medical conversations between deaf and hearing individuals with tabletop displays. Proceedings of the ACM Conference on Computer Supported Cooperative Work, CSCW: 147-156.

[20] Sauvageau, B. (2017). Hearing Children with Deaf Parents: The Impacts on Language Development. Lobe Blog. Retrieved from https://www.lobe.ca/en/blog/childrenshearing-health/hearing-children-deaf-parents

[21] Seek the World. (2018). Deaf Parents' Two Years Old Girl, Octavia Burke, Knows Three Languages. YouTube. Retrieved from https://www.youtube.com/watch?v=57TJPYgsYKo\&ab_cha nnel=SeektheWorld

[22] Skujins. A, (2017). What It's Like to Grow Up with Deaf Parents. Vice. Retrieved from https://www.vice.com/en/article/ne3bz7/what-its-like-togrow-up-with-deaf-parents

[23] Vogler, C et al., (2013). Mixed local and remote participation in teleconferences from a deaf and hard of hearing perspective. Proceedings of the 15th International ACM SIGACCESS Conference on Computers and Accessibility, ASSETS 2013. NonCommercial-NoDerivatives 4.0 International License. To view a copy of this license, visit http://creativecommons.org/licenses/by-nc-nd/4.0/ or send a letter to Creative Commons, PO Box 1866, Mountain View, CA 94042, USA. 